\title{
Problems with mapping the auroral oval and magnetospheric substorms
}

\author{
E. E. Antonova ${ }^{1 *}$, V. G. Vorobjev², I. P. Kirpichev ${ }^{3}$, O. I. Yagodkina ${ }^{2}$ and M. V. Stepanova ${ }^{4}$
}

\begin{abstract}
Accurate mapping of the auroral oval into the equatorial plane is critical for the analysis of aurora and substorm dynamics. Comparison of ion pressure values measured at low altitudes by Defense Meteorological Satellite Program (DMSP) satellites during their crossings of the auroral oval, with plasma pressure values obtained at the equatorial plane from Time History of Events and Macroscale Interactions during Substorms (THEMIS) satellite measurements, indicates that the main part of the auroral oval maps into the equatorial plane at distances between 6 and 12 Earth radii. On the nightside, this region is generally considered to be a part of the plasma sheet. However, our studies suggest that this region could form part of the plasma ring surrounding the Earth. We discuss the possibility of using the results found here to explain the ring-like shape of the auroral oval, the location of the injection boundary inside the magnetosphere near the geostationary orbit, presence of quiet auroral arcs in the auroral oval despite the constantly high level of turbulence observed in the plasma sheet, and some features of the onset of substorm expansion.
\end{abstract}

\section{Findings}

\section{Introduction}

Accurate mapping of the auroral oval onto the equatorial plane is necessary in determining the locations of substorm expansion phase onsets. In very early studies of auroral morphology, Akasofu (1964) showed that substorm onset is characterized by the brightening of the most equatorward auroral arc. Subsequent studies of dispersionless substorm injections (see Lopez et al. 1990 and Spanswick et al. 2010 and references therein) demonstrated that they are located near geostationary orbit, indicating that such injections take place deeply inside the magnetosphere. During the last few decades, however, the majority of studies of auroral substorms have focused predominantly on the geomagnetic tail and its dynamics. These studies have often relied on mapping the auroral oval structures to the equatorial plane along the magnetic field lines, calculated using various geomagnetic field models. This overall mapping approach has been termed "topological mapping" by Paschmann et al. (2002). However, the use of differing geomagnetic field models in the mapping process has produced conflicting results (see, for

\footnotetext{
* Correspondence: antonova@orearm.msk.ru

'Skobeltsyn Institute of Nuclear Physics, Lomonosov Moscow State

University, Moscow, Russia

Full list of author information is available at the end of the article
}

example, Hones et al. 1996, Weiss et al. 1997, Antonova et al. 2006, Xing et al. 2009).

Exclusion of a number of current systems from the geomagnetic field models serves to constrain the accurate topological mapping of auroral structures. For instance, existing models with a fixed predefined current geometry do not incorporate the current systems introduced by Antonova and Ganushkina (2000) and Antonova (2000), or the cut ring current (CRC). The topology of the CRC is very similar to the topology of the ordinary ring current (RC), and as such it can be considered a high latitude continuation of the ordinary ring current. The CRC occurs due to the fact that gradients of plasma pressure in the equatorial plane are predominantly directed towards the Earth at all magnetic local times (MLT), as shown by data from the Active Magnetospheric Particle Tracer Explorers/ Charge Composition Explorer (AMPTE/CCE) satellite obtained at geocentric distances up to $8.8 \mathrm{R}_{\mathrm{E}}$ (Lui and Hamilton 1992; DeMichelis et al. 1999) and later results from the Time History of Events and Macroscale Interactions during Substorms (THEMIS) mission (Kirpichev and Antonova 2011; Wang et al. 2011; Antonova et al. 2013) at greater distances, up to the dayside magnetopause. This suggests that the current system surrounding the Earth extends almost up to the dayside magnetopause on the dayside and is located between around 6-7 and 10-12 $R_{E}$ near

\section{实 Springer}

(c) 2016 Antonova et al. Open Access This article is distributed under the terms of the Creative Commons Attribution 4.0 International License (http://creativecommons.org/licenses/by/4.0/), which permits unrestricted use, distribution, and reproduction in any medium, provided you give appropriate credit to the original author(s) and the source, provide a link to the Creative Commons license, and indicate if changes were made. 
midnight. However, the characteristics of the geomagnetic field differ between the nightside and the dayside regions. On the nightside, the surface of minimum magnetic field values is located at the equatorial plane. Therefore the nighttime transverse currents are also concentrated near the equatorial plane. In contrast, on the dayside, due to the compression of the magnetic field lines, there are two surfaces of minimal magnetic field values shifted away from the equatorial plane, with one in each hemisphere. This leads to the dayside transverse current being spread along a field line, causing the integral current to be split into two branches, which leads to the appearance of CRC-type current lines. This type of current lines also appears in the magnetohydrodynamic (MHD) models of high latitude transverse currents (Liemohn et al. 2011). Initial estimates of CRC intensities have been made by Antonova et al. (2009a, b) and Kirpichev and Antonova (2014). Thus, the existence of the CRC, which is not included in existing geomagnetic field models with fixed geometry, poses a problem for mapping the auroral regions to the equatorial plane, or, more exactly, to the surface of minimal magnetic field values.

Since the very beginning of space exploration, direct measurements have shown (see Paschmann et al. 2002 and references therein) that the region between the plasmapause and daytime magnetopause is filled with plasma similar to that in the plasma sheet. Additionally, plasma sheet-like precipitations have been observed in the auroral oval at all MLTs, including the near noon region (Newell and Meng 1992; Starkov et al. 2002). Therefore, it is natural to assume that the auroral oval may be mapped onto the ring-shaped structure surrounding the Earth, which is filled with plasma similar to that in the near-Earth plasma sheet. To verify this important assumption, it is necessary to develop a mapping technique that is based on specific plasma features, socalled "natural tracers", which remain invariant along magnetic field lines. Such mapping has been termed "morphological mapping" (see Chapter 5 of the review by Paschmann et al. 2002).

Plasma pressure can be considered one such natural tracer, considering that the isotropic plasma pressure is conserved along a magnetic field line in the absence of field-aligned potential drop (Goertz and Baumjohann 1991) when the plasma is in magnetostatic equilibrium. Kirpichev and Antonova (2011) and Antonova et al. (2013) obtained the averaged distributions of plasma pressure, pressure anisotropy, and magnetic field near the equatorial plane at geocentric distances of $>6 \mathrm{R}_{\mathrm{E}}$ for all magnetic local times (MLT), using data from the THEMIS mission. Later, Antonova et al. (2014a) calculated the values of plasma parameter "beta", which represents the ratio of plasma pressure to magnetic pressure, in the region of minimal magnetic field values for all MLTs, using the Tsyganenko-
2001 geomagnetic field model. They showed the existence of a high-beta plasma ring surrounding the Earth. The values obtained for the currents generated by corresponding plasma pressure gradients are sufficiently strong to produce significant distortions of the geomagnetic field.

In this study, we analyze the problem of auroral oval mapping without geomagnetic field models. Our mapping is based on a comparison between plasma pressure distributions at ionospheric altitudes and those in the equatorial plane. The feasibility of such an analysis in regions with very low geomagnetic activity has been previously demonstrated by Antonova et al. (2014b).

\section{Methodology of morphological mapping}

We compare the ion pressure distributions between low altitudes and the equatorial plane, assuming that plasma is in magnetostatic equilibrium:

$$
[\mathbf{j} \times \mathbf{B}]=\nabla P,
$$

where $\mathbf{j}$ is the current density, $\mathbf{B}$ is the magnetic field, and $P$ is the plasma pressure. This condition describes the plasma configuration when the plasma velocity is much smaller than Alfvén and sound speeds. Previous studies have shown that plasma pressure is nearly isotropic in the high latitude nightside magnetosphere (Kirpichev and Antonova 2011; Wang et al. 2011, 2012; Antonova et al. 2013, 2014a), and on the dayside, the pressure anisotropy is less than 1.2-1.4. In magnetostatic equilibrium, the isotropic plasma pressure is nearly constant along magnetic field line and can be considered a "natural tracer" or a landmark of the field line when the plasma anisotropy is low (see, for example, Dubyagin et al. 2002, 2003). The auroral acceleration also affects the condition in which $P=$ const along a field line, decreasing the ion pressure in the regions of upward fieldaligned currents. In contrast, in the regions of downward field-aligned currents, the pressure is generally conserved (see the review of Paschmann et al. 2002). This means that the ion pressure measured at altitudes lower than the auroral acceleration region will be equal to or less than the ion pressure in the equatorial plane.

The distribution of plasma pressure at auroral latitudes has been obtained by Wing and Newell (1998) and Wing et al. (2013), using data from Defense Meteorological Satellite Program (DMSP) satellites. Wing and Newell (1998) used the modified Tsyganenko-1989 model to map the pressures from auroral latitudes into the equatorial plane. The plasma pressures in the plasma sheet at geocentric distances $>10 R_{E}$ are shown in Plate 1 of Wing and Newell (1998) and are larger than $0.2 \mathrm{nPa}$. It is well known that the typical value of the $\mathrm{Bx}$ component of the magnetic field in the tail lobes is around $20 \mathrm{nT}$, which gives a corresponding pressure of $0.16 \mathrm{nPa}$. 
Considering the total pressure balance across the plasma sheet, the plasma pressure in the center of the sheet should have a similar value (see Petrukovich et al. 1999 and references therein). Wang et al. (2001) compared the radial profiles of plasma pressure near to midnight (see Fig. 4 in this paper), obtained using the data from several high-apogee satellites and by mapping the DMSP ion pressure from ionospheric altitudes onto the equatorial plane (see Figure 4 of Wang et al. 2001). They showed that the plasma pressure obtained by Wing and Newell (1998) by mapping DMSP ion pressure onto the equatorial plane from ionospheric altitudes is larger than that measured by Explorer 45, International Sun-Earth Explorer (ISEE) 1 and 2, and Active Magnetospheric Particle Tracer Explorers/Ion Release Module (AMPTE/IRM) satellites on the equatorial plane. Tsyganenko and Mukai (2003) show that the averaged value of ion pressure obtained in the plasma sheet using Geotail data is equal to $0.229 \mathrm{nPa}$. Comparison of this value of plasma pressure with the values of ion pressures shown in Plate 1 of Wing and Newell (1998) also indicate that under quiet geomagnetic conditions the ion pressure obtained using the DMSP data is larger than that obtained in the plasma sheet using Geotail data. Therefore, under quiet geomagnetic conditions, the auroral oval must be mapped closer to the Earth than is possible using the Tsyganenko-1989 model. Recently, Wing et al. (2013) obtained the distribution of plasma pressure at the latitudes of the auroral oval for different phases of a magnetospheric substorm, using DMSP satellite data (see Plate 6 of Wing et al. 2013). In this, plasma pressures were found to range predominantly from 0.2 to $0.8 \mathrm{nPa}$. However, Wing et al. (2013) did not investigate the possible relationships between pressure distributions and different types of auroral electron precipitation.

Vorobjev and Yagodkina (2005) and Vorobjev et al. (2013) developed the Interactive Auroral Precipitation
Model (APM) (PGIA 2015) based on the classification of electron precipitation types proposed by Starkov et al. (2002). In this model, the auroral oval precipitation (AOP) region is the area of structured precipitation within the auroral oval, the diffuse auroral zone (DAZ) is the region of diffuse auroral precipitation located equatorward of the AOP, and the soft diffuse precipitation (SDP) area is the region of soft diffuse precipitation located poleward of the AOP. Electron precipitating fluxes were measured by the DMSP F6 and F7 satellites in 1986 (APL Space Department 2015), which was a year of minimum of solar activity. All data were divided into eight MLT sectors, and the level of geomagnetic activity was characterized by AL and Dst indices. Inside each sector, the relationships between the corrected geomagnetic latitudes of the boundaries of each type of precipitation and the geomagnetic activity were established using a generalized regression technique. The results of this model provide distributions of the different types of auroral electron precipitation, as a function of corrected geomagnetic latitude and local geomagnetic time under different levels of geomagnetic activity.

Ion pressure is the dominant contributor to plasma pressure and can be obtained through analysis of the auroral ion precipitating fluxes, as previously shown by Wing and Newell (1998), Stepanova et al. (2004, 2008), and Wing et al. (2013). Comparison of ion pressure distributions, obtained in this way, with the boundaries of AOP, DAZ, and SDP enables the determination of ion pressures for each region. A comparison of these values with the pressure in the equatorial plane can thus provide important information about the mapping of the auroral oval.

\section{Results of morphological mapping of the AOP and discussion}

Figure 1a shows the location of the AOP (green), DAZ (blue), and SDP (red) regions under very quiet geomagnetic

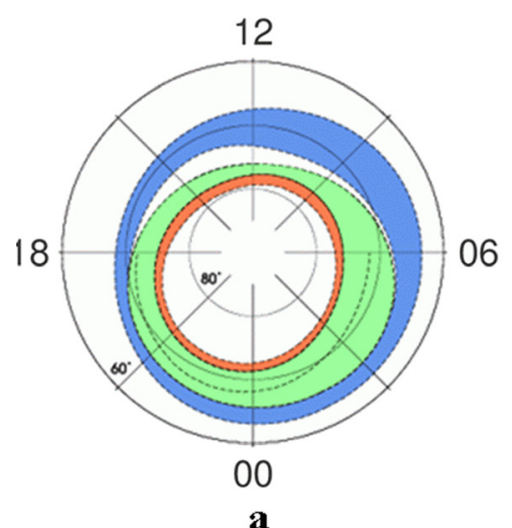

a

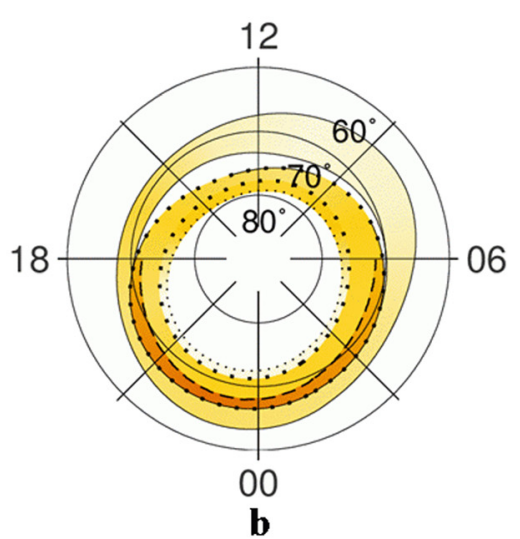

b

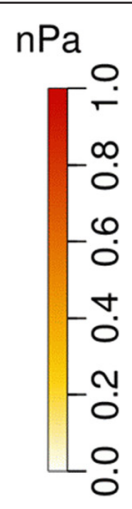

Fig. 1 Location of a the AOP, DAZ, and SDP regions, and $\mathbf{b}$ the global distribution of ion pressures during quiet conditions. a Location of the AOP (green), DAZ (blue), and SDP (red) regions, and $\mathbf{b}$ the global distribution of ion pressure in the range $0.3-30 \mathrm{keV}$ at ionospheric altitudes of around $110 \mathrm{~km}$, obtained using data from the DMSP satellites for very quiet geomagnetic conditions of $\mathrm{AL}=-100 \mathrm{nT}$ and Dst $=-5 \mathrm{nT}$ 
conditions ( $\mathrm{AL}=-100 \mathrm{nT}$, Dst $=-5 \mathrm{nT})$. As can be seen from this figure, all three regions have a ring-like shape. Figure $1 \mathrm{~b}$ shows the global distribution of ion pressures obtained from DMSP data for the same time interval and under the same geomagnetic conditions. The pressures are indicated by the color scale on the right-hand side of the figure. Bold dotted lines indicate the locations of the polar and equatorial boundaries of the AOP region, defining the traditional auroral oval; while the thin dotted line indicates the polar boundary of the SDP area. Figure 2a, b shows the locations of the AOP, DAZ, and SDP regions, as well as plasma pressures and region boundaries under moderately disturbed geomagnetic conditions $(\mathrm{AL}=-600$ $\mathrm{nT}$, Dst $=-20 \mathrm{nT}$ ). As expected, the area covered by the auroral oval increases with the increase in geomagnetic activity. Figures $1 \mathrm{~b}$ and $2 \mathrm{~b}$ indicate that over most of the AOP region, the ion pressure is larger than $0.2 \mathrm{nPa}$ under both quiet and disturbed conditions. It can also be seen that the ion pressure reaches around $1 \mathrm{nPa}$ at the equatorial boundary of the AOP region. The pressures in the SDP are typically lower than $0.2 \mathrm{nPa}$. It should be noted that the ion pressure is smaller than the total plasma pressure, as the electron pressure is not considered, and therefore the corresponding pressure in the equatorial plane should be even higher.

Figures $3 \mathrm{a}, \mathrm{b}$ and $4 \mathrm{a}, \mathrm{b}$ show the distributions of pressure at the equatorial plane and the pressure anisotropy obtained from THEMIS measurements, averaged within the same MLT intervals under the same geomagnetic conditions as those in Figs. 1 and 2, respectively. The black lines in Figs. 3a and 4a show the contours of constant pressure in the equatorial plane. Red lines show the positions of the magnetopause, obtained using the model presented by Shue et al. (1998). It can be seen from these figures that the pressure increases with an increase in geomagnetic activity. For instance, at the boundary of the plasma ring surrounding the Earth, the pressure is around $0.2 \mathrm{nPa}$ during the quiescent period, but increases to around $0.3 \mathrm{nPa}$ during moderately disturbed conditions. Analysis of the levels of anisotropy (Figs. 3b and 4b) indicates that anisotropy decreases with an increase in geomagnetic activity on the dayside. It should be noted that the dataset used to construct Fig. 3 is much larger than that for Fig. 4. The distributions obtained in this way are in good agreement with the nighttime pressure distributions at geocentric distances of more than $10 R_{E}$ provided by the statistical model of Tsyganenko and Mukai (2003).

Comparing Figs. $1 \mathrm{~b}$ and $3 \mathrm{a}$, it can be seen that the ion pressures across the majority of the AOP region are in good agreement with the total (electron and ion) pressures in the equatorial plane in the plasma ring surrounding the Earth. The same conclusion can be reached through an analysis of Figs. 2b and 4a. Differences of around $15 \%$ of the total values are observed in the region of the downward field-aligned currents and can be much greater in the upward field-aligned current regions. However, in both cases, the total plasma pressure at the equatorial plane is larger than the ion pressure at ionospheric altitudes. Large values of ion pressure in the most part of AOP region mean in such a case that AOP is not mapped to the plasma sheet proper, for which the plasma pressure is smaller than $0.2 \mathrm{nPa}$. It is mapped into the surrounding of the Earth plasma ring. However, more exact AOP mapping requires more careful analysis, including the calculations of field-aligned potential drop and its effect on the ion precipitations leading to reduction of the ion pressure. Plasma sheet proper can be mapped into SDP where DMSP plasma pressure does not exceed $0.2 \mathrm{nPa}$.

Obtained AOP mapping without using any magnetic field model with predefined geometry of current systems can help to explain some features of auroral and substorm dynamics. For instance, mapping of the main part of the AOP region into the plasma ring surrounding the
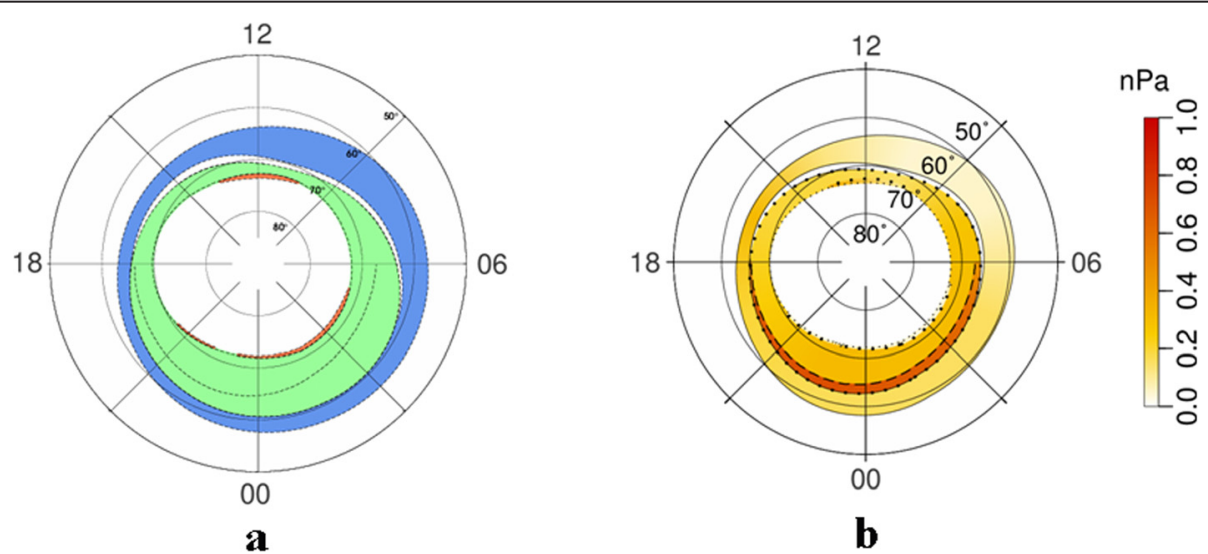

Fig. 2 Location of a the AOP, DAZ, and SDP regions and $\mathbf{b}$ the global distribution of ion pressures during disturbed conditions, as for Fig. 1, but for moderately disturbed geomagnetic conditions of $\mathrm{AL}=-600 \mathrm{nT}$ and Dst $=-20 \mathrm{nT}$ 


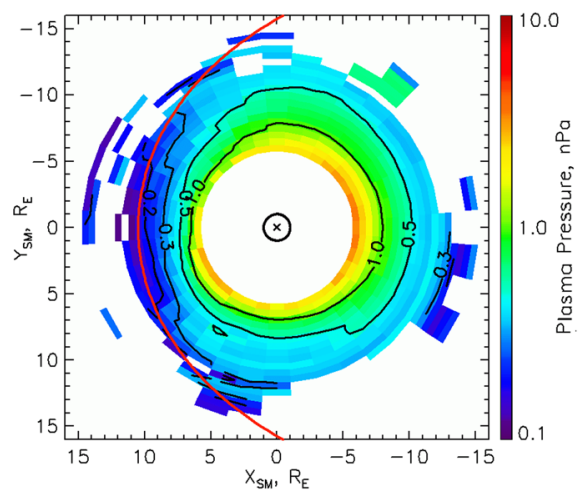

a

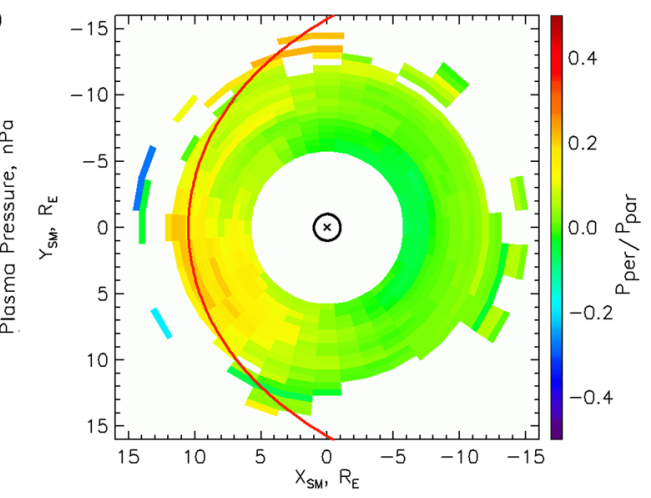

b

Fig. 3 Plasma pressure and pressure anisotropy in the equatorial plane during low geomagnetic activity. Results of the calculation of a pressure and $\mathbf{b}$ pressure anisotropy in the equatorial plane, from data of the THEMIS mission, for $A L=-100 \mathrm{nT}$ and Dst $=-5 \mathrm{nT}$

Earth can logically explain the well-defined circular shape of the auroral oval.

The existence of a drop in field-aligned potential is a very important feature of auroral dynamics. Simple evaluations have shown (see, for example, Kornilov et al. 2008) that in the absence of such a field-aligned potential drop, the energy flux of precipitating electrons is near to the registration threshold of polar imagers (around $0.5 \mathrm{erg} \mathrm{cm}^{-2} \mathrm{~s}^{-1}$ ) and ground-based measurements. This implies that only upward field-aligned currents can produce visible auroras, which is supported by the comprehensive analyses of Ohtani et al. (2010) and Korth et al. (2014). The location of the upward region 2 current sources (Iijima and Potemra 1976) inside the magnetosphere at comparatively small geocentric distances is well known. Further, analysis of the results of Xing et al. (2009) demonstrates that the source of upward-aligned region 1 currents is at a geocentric distance of around $11 \mathrm{R}_{\mathrm{E}}$, which corresponds to a location inside the plasma ring surrounding the Earth.
Over a long period of scientific investigation, the existence of a dispersionless substorm injection boundary near to the geostationary orbits has been difficult to understand (see Lopez et al. 1990; Spanswick et al. 2010 and references therein), under the assumption that the region of substorm onset is mapped into the geomagnetic tail. Isolated substorm onset was identified by Akasofu (1964) at the equatorial boundary of the auroral oval, without any auroral activity to the north (see the reviews of Akasofu 2004). According to our results, the AOP region equatorial boundary is mapped to a geocentric distance of 6-7 $R_{E}$, which supports the models of substorm onsets occurring near to Earth, such as current disruption (see the review of Lui 2011) and magnetosphere-ionosphere interactions (Antonova 2002; Stepanova et al. 2002).

One of the main problems in understanding the high latitude magnetosphere and substorm dynamics is the high-level turbulence that is constantly observed within the plasma sheet. Intensive studies of this turbulence began with the identification and analysis of bursty-bulk-

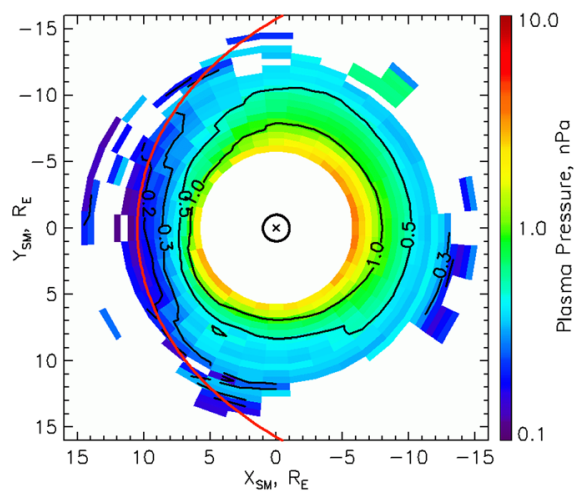

a

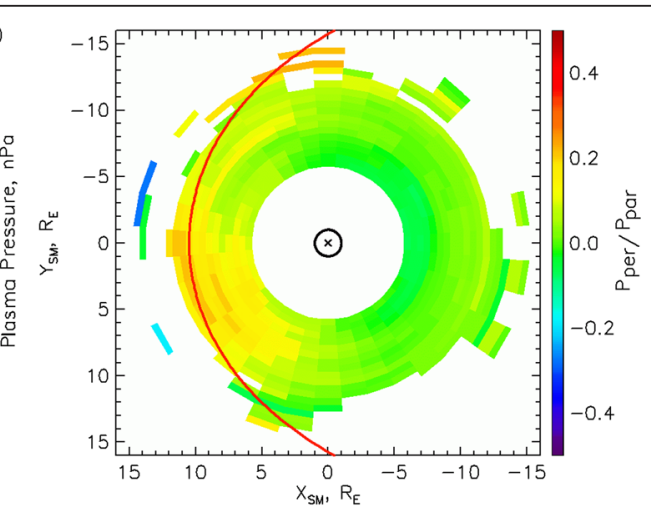

b

Fig. 4 Plasma pressure and pressure anisotropy in the equatorial plane during high geomagnetic activity. Results of the calculation of a pressure and $\mathbf{b}$ pressure anisotropy in the equatorial plane, from data of the THEMIS mission, for $A L=-600 \mathrm{nT}$ and Dst $=-20 \mathrm{nT}$ 
flow (BBF) events by Baumjohann et al. $(1989,1990)$ and continued with the investigation of different aspects of the turbulence, including eddy-diffusion, scaling, and intermittency (see, for example, Borovsky et al. 1997; Angelopoulos et al. 1999; Antonova et al 2000; Troshichev et al. 2002; Vörös et al. 2004; Uritsky et al. 2009). However, it is also well known that auroral arcs are well defined and can be very stable between geomagnetic disturbances. For this reason, it is necessary to explain the co-existence of stable auroral arcs in the auroral oval with the BBFs and associated turbulent fluctuation in the plasma sheet. The mapping of the AOP region to the plasma ring surrounding the Earth removes this problem, thanks to the braking of highspeed ion flows in the near-Earth central plasma sheet at geocentric distances of more than $9 \mathrm{R}_{\mathrm{E}}$ (Shiokawa et al. 1997), as well as a decrease in the degree of plasma sheet fluctuation at geocentric distances less than around $10 R_{E}$ (Stepanova et al. 2009, 2011; Pinto et al. 2011).

\section{Conclusions}

Our analysis demonstrates the necessity to improve existing mapping techniques by using specific plasma features, so-called "natural tracers", which conserve their characteristic signatures along magnetic field lines. We show here that plasma pressure can be successfully used as one such "natural tracer".

A comparison of the pressure distributions measured in the equatorial plane by the THEMIS satellites with those measured by DMSP satellite above the auroral oval under both quiet and moderately disturbed geomagnetic conditions, reveals the role of the plasma ring surrounding the Earth in substorm dynamics. The results indicate that the popular approach of mapping the auroral oval into the plasma sheet must be modified and that the main part of the oval, especially its equatorial boundary, should not be mapped into the plasma sheet proper, but rather into the plasma ring surrounding the Earth. Such mapping explains the ring-like shape of the auroral oval, the location of the injection boundary inside the magnetosphere near the geostationary orbit, and the presence of quiet auroral arcs in the auroral oval despite the high level of plasma turbulence constantly observed in the plasma sheet. Subsequent studies to further verify and enhance the precision of these results should focus on an analysis of the processes occurring at geocentric distances between around $6-7$ and $10-12 R_{E}$.

\footnotetext{
Abbreviations

AOP: auroral oval precipitation; APM: auroral precipitation model; CRC: cut ring current (a high latitude continuation of the ordinary ring current); DAZ: region of diffuse auroral precipitation located equatorward of the AOP; $\mathrm{RC}$ : ordinary ring current; SDP: region of soft diffuse precipitation located poleward of the AOP.
}

\section{Competing interests}

The authors declare that they have no competing interests.

\section{Authors' contributions}

All authors offered the same contribution to this study. All authors read and approved the final manuscript.

\section{Authors' information}

The authors have been in close collaboration between their four organizations for many years.

\section{Acknowledgements}

The DMSP particle detectors were designed by Dave Hardy of AFRL, and data were obtained from JHU/APL. We acknowledge NASA contract NAS5-02099 and V. Angelopoulos for the use of data from the THEMIS Mission. Specifically: C. W. Carlson and J. P. McFadden for the use of ESA data, and D. Larson and R. P. Lin for the use of SST data. This work was supported by grant from the Russian Foundation for Basic Research No 15-05-04965 (E.E. Antonova, I.P. Kirpichev), the Program of the RAS Presidium No 9 (V. G. Vorobjev, O. I. Yagodkina) and Vicerrectoria de Investigacion, Desarrollo e Innovacion (VRIDEI), Universidad de Santiago de Chile (USACH), grant DICYT 041531SSSA, and the Proyectos Basales grant 041531SSSA_INTEXCELE (M.V. Stepanova).

\section{Author details}

'Skobeltsyn Institute of Nuclear Physics, Lomonosov Moscow State University, Moscow, Russia. ${ }^{2}$ Polar Geophysical Institute, Apatity, Murmansk Region, Russia. ${ }^{3}$ Space Research Institute RAS, Moscow, Russia. ${ }^{4}$ Physics Department, Science Faculty, Universidad de Santiago de Chile, Santiago, Chile.

Received: 30 April 2015 Accepted: 1 October 2015

Published: 12 October 2015

\section{References}

Akasofu SI (1964) The development of the auroral substorm. Planet Space Sci 12:273-282. doi:10.1016/0032-0633(64)90151-5

Akasofu SI (2004) Several 'controversial' issues on substorms. Space Sci Rev 113:1-40. doi:10.1023/B:SPAC.0000042938.57710.fb

Angelopoulos V, Mukai T, Kokubun S (1999) Evidence for intermittency in Earths plasma sheet and implications for self-organized criticality. Phys Plasmas 6(11):4161-4168. doi:10.1063/1.873681

Antonova EE (2000) Large scale magnetospheric turbulence and the topology of magnetospheric currents. Adv Space Res 25(7/8):1567-1570. doi:10.1016/ S0273-1177(99)00669-9

Antonova EE (2002) The results of INTERBALL/Tail observations, the inner magnetosphere substorm onset and particle acceleration. Adv Space Res 30(7):1671-1676. doi:10.1016/S0273-1177(02)00434-9

Antonova EE, Ganushkina NY (2000) Inner magnetospheric currents and their role in the magnetosphere dynamics. Phys Chem Earth (C) 25(1-2):23-26. doi:10.1016/S0273-1177(02)00434-9

Antonova EE, Kirpichev IP, Stepanova MV (2006) Field-aligned current mapping and the problem of the generation of magnetospheric convection. Adv Space Res 38:1637-1641. doi:10.1016/j.asr.2005.09.042

Antonova EE, Kirpichev IP, Stepanova MV, Orlova KG, Ovchinnikov IL (2009a) Topology of the high latitude magnetosphere during large magnetic storms and the main mechanisms of relativistic electron acceleration. Adv Space Res 43:628-633. doi:10.1016/j.asr.2008.09.011

Antonova EE, Kirpichev IP, Ovchinnikov IL, Orlova KG, Stepanova MV (2009b) High latitude magnetospheric topology and magnetospheric substorm. Ann Geophysicae 27:4069-4073. doi:10.5194/angeo-27-4069-2009

Antonova EE, Kirpichev IP, Vovchenko W, Stepanova MV, Riazantseva MO, Pulinets MS, Ovchinnikov IL, Znatkova SS (2013) Characteristics of plasma ring, surrounding the Earth at geocentric distances $\sim 7-10 R_{E}$, and magnetospheric current systems. J Atmos Sol Terr Phys 99:85-91. doi:10.1016/j.jastp.2012.08.013

Antonova EE, Kirpichev IP, Stepanova MV (2014a) Plasma pressure distribution in the surrounding the Earth plasma ring and its role in the magnetospheric dynamics. J Atmos Sol Terr Phys 115-116:32-40. doi:10.1016/ j.jastp.2013.12.005

Antonova EE, Vorobjev VG, Kirpichev IP, Yagodkina OI (2014b) Comparison of the plasma pressure distributions over the equatorial plane and at low altitudes under magnetically quiet conditions. Geomag Aeron 54:278-281. doi:10.1134/S0016793214030025

APL Space Department 2015. http://sd-www.jhuapl.edu/ 
Baumjohann W, Paschmann G, Cattell CA (1989) Average plasma properties in the central plasma sheet. J Geophys Res 94:6597-6606. doi:10.1029/ JA094iA06p06597

Baumjohann W, Paschmann G, Lühr H (1990) Characteristics of high-speed flows in the plasma sheet. J Geophys Res 95:3801-3809. doi:10.1029/ JA095iA04p03801

Borovsky JE, Elphic RC, Funsten HO, Thomsen MF (1997) The Earth's plasma sheet as a laboratory for flow turbulence in high- $\beta$ MHD. J Plasma Phys 57:1-34. doi:10.1017/S0022377896005259

DeMichelis P, Daglis IA, Consolini G (1999) An average image of proton plasma pressure and of current systems in the equatorial plane derived from AMPTE/CCE-CHEM measurements. J Geophys Res 104A:28615-28624. doi:10.1029/1999JA900310

Dubyagin SV, Sergeev VA, Kubyshkina MV (2002) On the remote sensing of plasma sheet from low-altitude spacecraft. J Atmos Sol Terr Phys 64(5-6):567-572. doi:10.1016/S1364-6826(02)00014-7

Dubyagin SV, Sergeev VA, Carlson CW, Marple SR, Pulkkinen TI, Yahnin AG (2003) Evidence of near-Earth breakup location. Geophys Res Lett 30:6. doi:10.1029/ 2002GL016569

Goertz CK, Baumjohann W (1991) On the thermodynamics of the plasma sheet. J Geophys Res 96(A12):20991-20998. doi:10.1029/91JA02128

Hones EW, Thomsen MF, Reeves GD, Weiss LA, McComas DJ (1996) Observational determination of magnetic connectivity of the geosynchronous region of the magnetosphere to the auroral oval. J Geophys Res 101(A2):2629-2640, doi:10.1029/95JA00418

lijima T, Potemra TA (1976) Field-aligned currents in the dayside cusp observed by TRIAD. J Geophys Res 81(12):5971-5979. doi:10.1029/JA081i034p0597

Kirpichev IP, Antonova EE (2011) Plasma pressure distribution in the equatorial plane of the Earth's magnetosphere at geocentric distances of 6-10RE according to the international THEMIS mission data. Geomag Aeron 51:450-455. doi:10.1134/ S0016793211040049

Kirpichev IP, Antonova EE (2014) Estimation of the current density and analysis of the geometry of the current system surrounding the Earth. Cosmic Research 52:52-60. doi:10.1134/S0010952514010043

Kornilov IA, Antonova EE, Kornilova TA, Kornilov OI (2008) Fine structure of auroras during auroral breakup according to the ground-based and satellite observations. Geomag Aeron 48(1):7-19. doi:10.1134/S0016793208010027

Korth $\mathrm{H}$, Zhang $Y$, Anderson BJ, Sotirelis T, Waters CL (2014) Statistical relationship between large scale upward field-aligned currents and electron precipitation. J Geophys Res Space Phys 119:6715-6731. doi:10.1002/2014JA019961

Liemohn MW, De Zeeuw DL, Ilie R, Ganushkina NY (2011) Deciphering magnetospheric cross-field currents. Geophys Res Lett 38. doi:10.1029/ 2011GL049611

Lopez RE, Sibeck DG, McEntire RW, Krimigis SM (1990) The energetic ion substorm injection boundary. J Geophys Res 95(A1):109-117. doi:10.1029/ JA095iA01p00109

Lui ATY, Hamilton DC (1992) Radial profile of quiet time magnetospheric parameters. J Geophys Res 97(A12):19325-19332. doi:10.1029/92JA01539

Lui ATY (2011) Revisiting Time History of Events and Macroscale Interactions during Substorms (THEMIS) substorm events implying magnetic reconnection as the substorm trigger. J Geophys Res 116. doi:10.1029/ 2010JA016078

Newell PT, Meng C-I (1992) Mapping the dayside ionosphere to the magnetosphere according to particle precipitation characteristics. Geophys Res Lett 19(6):609-612. doi:10.1029/92GL00404

Ohtani S, Wing S, Newell PT, Higuchi T (2010) Locations of night-side precipitation boundaries relative to $\mathrm{R} 2$ and $\mathrm{R} 1$ currents. J Geophys Res 115:A10233. doi:10.1029/2010JA015444

Paschmann G, Haaland S, Treumann R (2002) Auroral plasma physics. Space Sci Rev 103:1-485. doi:10.1023/A:1023030716698

Petrukovich AA, Mukai T, Kokubun S, Romanov SA, Saito Y, Yamamoto T, Zelenyi LM (1999) Substorm associated pressure variations in the magnetotail plasma sheet and lobe. J Geophys Res 104(3):4501-4513. doi:10.1029/98JA02418

PGIA 2015. http://apm.pgia.ru/

Pinto V, Stepanova M, Antonova EE, Valdivia JA (2011) Estimation of the eddy diffusion coefficients in the plasma sheet using THEMIS satellite data. J Atmos Sol Terr Phys 73(11-12):1472-1477. doi:10.1016/ j.jastp.2011.05.007

Shiokawa K, Baumjohann W, Haerendel G (1997) Braking of high-speed flows in the near-Earth tail. Geophys Res Lett 24(10):1179-1182. doi:10.1029/ 97GL01062
Shue J-H, Song P, Russell CT, Steinberg JT, Cgao JK, Zastenker G, Vaisberg OL, Kokubun S, Singer HJ, Detman TR, Kawano H (1998) Magnetopause location under extreme solar wind conditions. J Geophys Res 103(A8):17691-17700. doi:10.1029/98JA011031

Spanswick E, Reeves GD, Donovan E, Friedel RHW (2010) Injection region propagation outside of geosynchronous orbit. J Geophys Res 115. doi:10.1029/2009JA015066

Starkov GV, Rezhenov BV, Vorobjev VG, Feldstein YI (2002) Dayside auroral precipitation structure. Geomag Aeron 42(2):176-183, In Russian

Stepanova MV, Antonova EE, Bosqued JM, Kovrazhkin RA, Aubel KR (2002) Asymmetry of auroral electron precipitations and its relationship to the substorm expansion phase onset. J Geophys Res 107:A7. doi:10.1029/ 2001JA003503

Stepanova M, Antonova EE, Bosqued JM, Kovrazhkin R (2004) Radial plasma pressure gradients in the high latitude magnetosphere as sources of instabilities leading to the substorm onset. Adv Space Res 33(5):761-768. doi:10.1016/S0273(03)00634-3

Stepanova M, Antonova EE, Bosqued JM (2008) Radial distribution of the inner magnetosphere plasma pressure using low-altitude satellite data during geomagnetic storm: The March 1-8, 1982 event. Adv Space Res 41(10):1658-1665. doi:10.1016/j.asr.2007.06.002

Stepanova M, Antonova EE, Paredes-Davis D, Ovchinnikov IL, Yermolaev YI (2009) Spatial variation of eddy-diffusion coefficients in the turbulent plasma sheet during substorms. Ann Geophys 27(4):1407-1411. doi:10.5194/angeo-27-1407-2009

Stepanova M, Pinto V, Valdivia JA, Antonova EE (2011) Spatial distribution of the eddy diffusion coefficients in the plasma sheet during quiet time and substorms from THEMIS satellite data. J Geophys Res 116. doi:10.1029/ 2010JA015887

Troshichev OA, Antonova EE, Kamide Y (2002) Inconsistency of magnetic field and plasma velocity variations in the distant plasma sheet: Violation of the "frozen-in" criterion? Adv Space Res 30(12):2683-2687. doi:10.1016/ S0273-1177(02)80382-9

Tsyganenko NA, Mukai T (2003) Tail plasma sheet models derived from Geotail data. J Geophys Res 108:A3. doi:10.1029/2002JA009707

Uritsky VM, Donovan E, Klimas AJ, Spanswick E (2009) Collective dynamics of bursty particle precipitation initiating in the inner and outer plasma sheet. Ann Geophys 27:745-753. doi:10.5194/angeo-27-745-2009

Vorobjev VG, Yagodkina Ol (2005) Effects of magnetic activity on the global distribution of auroral precipitating zones. Geomag Aeron 45(4):438-444

Vorobjev VG, Yagodkina OI, Katkalov YV (2013) Auroral precipitation model and its applications to ionospheric and magnetospheric studies. J Atmosp Solar-Terr Phys 102:157-171. doi:10.1016/j.jastp.2013.05.007

Vörös Z, Baumjohann W, Nakamura R, Volwerk M, Runov A, Zhang TL, Eichelberger HU, Treumann R, Georgescu E, Balogh A, Klecker B, Rème H (2004) Magnetic turbulence in the plasma sheet. J Geophys Res 109A:11215 doi:10.1029/2004JA010404

Wang C-P, Lyons LR, Chen MW, Wolf RA (2001) Modeling the quiet time inner plasma sheet protons. J Geophys Res 106(A4):6161-6178. doi:10.1029/ 2000JA000377

Wang C-P, Gkioulidou M, Lyons LR, Wolf RA, Angelopoulos V, Nagai T, Weygand JM, Lui ATY (2011) Spatial distributions of ions and electrons from the plasma sheet to the inner magnetosphere: comparisons between THEMIS-Geotail statistical results and the Rice convection model. J Geophys Res 116A:11216. doi:10.1029/ 2011JA016809

Wang C-P, Zaharia SG, Lyons LR, Angelopoulos V (2012) Spatial distributions of ion pitch angle anisotropy in the near-Earth magnetosphere and tail plasma sheet. J Geophys Res Space Phys 118:244-255. doi:10.1029/2012JA018275

Weiss LA, Thomsen MF, Reeves GD, McComas DJ (1997) An examination of the Tsyganenko (T89a) field model using a database of two-satellite magnetic conjunctions. J Geophys Res 102(A3):4911-4918. doi:10.1029/96JA02876

Wing S, Newell PT (1998) Central plasma sheet ion properties as inferred from ionospheric observations. J Geophys Res 103(A4):6785-6800. doi:10.1029/ 97JA02994

Wing S, Gkioulidou M, Johnson JR, Newell PT, Wang C-P (2013) Auroral particle precipitation characterized by the substorm cycle. J Geophys Res Space Phys 118:1022-1039. doi:10.1002/jgra.50160

Xing X, Lyons LR, Angelopoulos V, Larson D, McFadden J, Carlson C, Runov A, Auster U (2009) Azimuthal plasma pressure gradient in quiet time plasma sheet. Geophys Res Lett 36(14), L14105. doi:10.1029/2009GL038881 